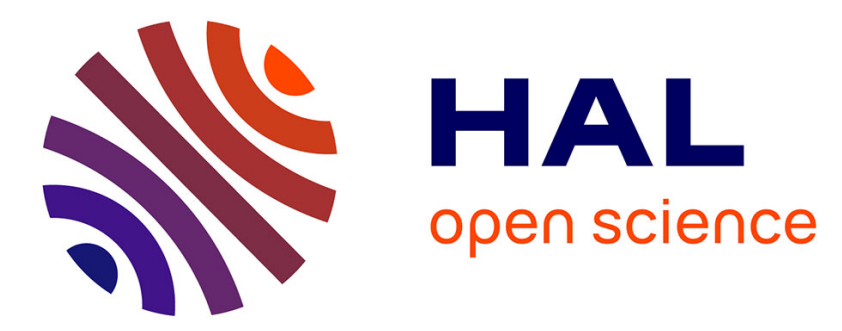

\title{
Bidirectional Data Management in Factory Planning and Operation
}

\author{
Uwe Dombrowski, Jonas Wullbrandt, Alexander Karl
}

\section{To cite this version:}

Uwe Dombrowski, Jonas Wullbrandt, Alexander Karl. Bidirectional Data Management in Factory Planning and Operation. IFIP International Conference on Advances in Production Management Systems (APMS), Sep 2019, Austin, TX, United States. pp.303-311, 10.1007/978-3-030-29996-5_35 . hal-02460512

\section{HAL Id: hal-02460512 \\ https://hal.inria.fr/hal-02460512}

Submitted on 30 Jan 2020

HAL is a multi-disciplinary open access archive for the deposit and dissemination of scientific research documents, whether they are published or not. The documents may come from teaching and research institutions in France or abroad, or from public or private research centers.
L'archive ouverte pluridisciplinaire HAL, est destinée au dépôt et à la diffusion de documents scientifiques de niveau recherche, publiés ou non, émanant des établissements d'enseignement et de recherche français ou étrangers, des laboratoires publics ou privés. 


\title{
Bidirectional data management in factory planning and operation
}

\author{
Uwe Dombrowski $^{1}$, Jonas Wullbrandt ${ }^{1 *}$, Alexander Karl ${ }^{1}$ \\ ${ }^{1}$ Institute for Advanced Industrial Management (IFU) \\ Technische Universität Braunschweig, Langer Kamp 19, 38106 Braunschweig, Germany \\ *Corresponding author. Tel: +49 531391 2704, E-mail: j.wullbrandt@tu-bs.de
}

\begin{abstract}
Due to a growing number of product variants, shorter lead times, and global supply chains, planning and launching production systems is becoming increasingly important. Therefore, managing the period of production ramp-up becomes a competitive advantage. To handle the increasing complexity and uncertainty in this special phase, data availability is necessary in terms of efficient decision making. However, in this early phase of the product and production system lifecycle, data quantity and quality are not guaranteed. This is due to the degree of novelty of processes, technologies and human behaviors in this special phase. In this paper it will be analyzed that selected data from the factory planning phase as well as the factory operation phase needs to be jointly processed by ramp-up involved personnel as value adding information. Finally, the presented use case, as well as the derived data management approach, will help companies to better manage production ramp-ups in the future.
\end{abstract}

Keywords: Production ramp-up, Digital factory, Data management

\section{Introduction}

Due to shorter product lifecycles and growing range of product varieties, the ramp-up phase, which is the transition from factory planning to factory operation phase, becomes increasingly important [1]. In addition, the digital transformation of products and processes leads to higher availability of data in the product development cycle. In the planning phase, the digital factory approach supports production planning departments with a "network of digital models, methods and tools (...), which are integrated by a consistent data management." [2] In the operating phase, the interconnection of people, products and other resources in form of cyber-physical production systems focuses on collecting, analyzing and providing real-time data in order to improve value-added processes [3]. In order to ensure a timely and costefficient ramp-up phase, the coordinated management of planning data and real data is crucial. [4] Therefore, the purpose of this paper is to close the "Ramp-up data gap" by identifying the two levers "Exploiting digital factory planning tools" and "Enrichment of planning data with real data". After discussing the characteristics of both fields of action practical experiences with bidirectional data management in an innovative test environment are presented. The paper results in recommendations on how to improve planning accuracy in the digital factory as well as the factory operations phase. 


\section{Production ramp-up phase as the transition from factory planning to factory operation}

\subsection{The Ramp-up data gap}

Production ramp-up phase can be described as the link between the product development phase and the series fabrication process and therefore represents an important integral function when it comes to the physical implementation of a products' value-added processes (compare Fig. 1) [5], [6]. The conflicting factors "low production capacity" and "high production demand" are characteristic of this special period. High demand arises because the product is new and market request is high. Low production capacity results from instable processes, little knowledge about socio-technical systems interactions as well as low qualification levels of involved employees [7].

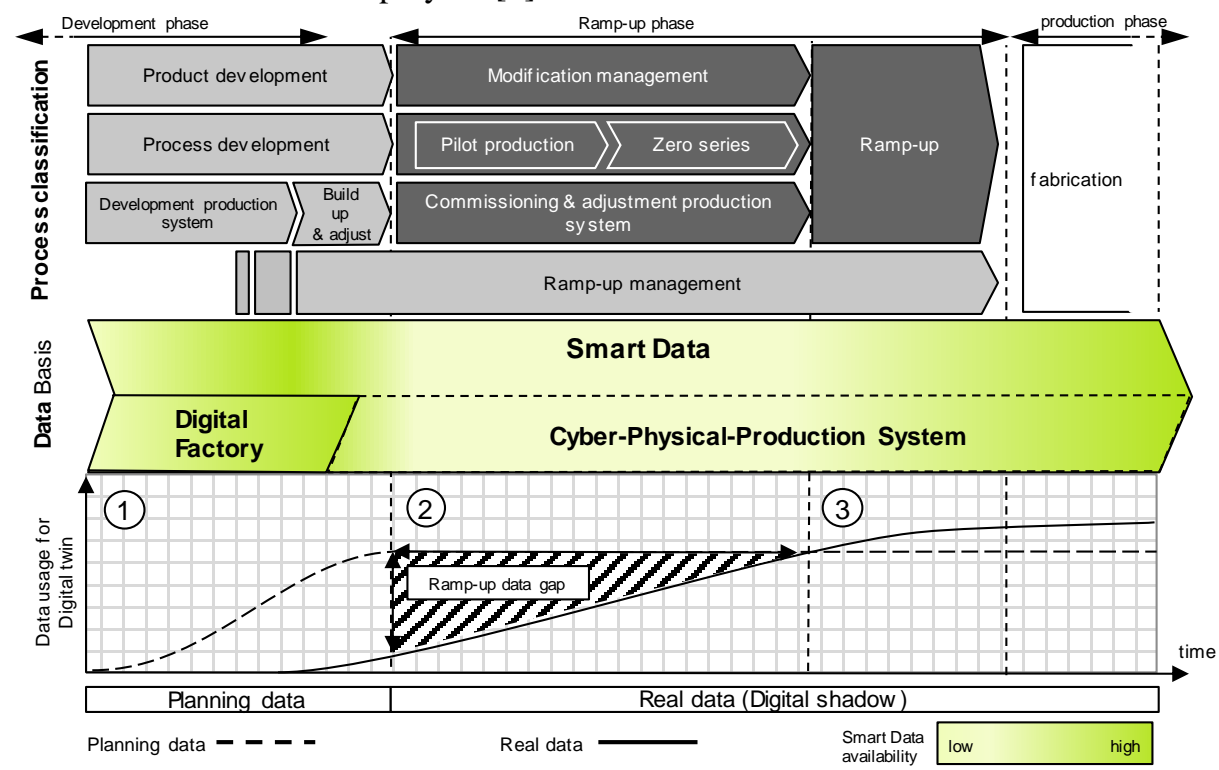

Figure 1: Process organization of production ramp-up, based on [5]

As illustrated in Fig. 1, a fundamental data basis along the whole product development process is necessary in order to make use of smart data in all different phases. Especially in the instable and critical production ramp-up phase it can be beneficial in terms of time-to-market reduction to manage high quality planning data from the factory planning phase as well as real operating data bidirectional [4]. From the moment the physical production system is built up, real data availability in form of a Digital shadow is beneficial. This is because real data is more accurate than historical data and therefore necessary in order to adjust planning data in the digital factory. This, in turn, can be described as the Digital twin, in which real data can be used in test scenarios to simulate alternatives virtually. Useful improvements can then by applied to the real factory operation phase. In general one can say that Industrie 4.0 leads to real-time data availability (digital shadow), which, if integrated in the digital twin by a 
consistent data management, results in highest planning accuracy in the digital factory as well as the factory operations [8]. [However, in the early production system ramp-up phase realdata is often unavailable because data generating sensors and technologies in the cyber-physical system are not installed, interconnected and tested yet. Therefore, DOMBROWSKI et. al. define the dashed field in Fig. 1 as "Ramp-up data gap" [5]. In order to minimize this gap and secure an integrated bidirectional data management in the ramp-up phase it is necessary to define two different levers that are described in the following:

1. Lever 1 - Exploiting digital factory planning tools: What tools and methods from the digital factory can be used in order to process and provide high qualitative planning data in the ramp-up phase?

2. Lever 2 - Enrichment of planning data: What real data is available from the production phase and can be useful in order to complement or enrich planning data for ramping-up the production?

\subsection{Lever 1: Exploiting digital factory planning tools}

The planning process of a factory involves the systematic, goal-oriented and phase-structured procedure, which is carried out with the aid of methods and tools. [9] Numerous approaches and concepts for planning a factory have been developed and discussed in the literature. The approaches mainly differ only in the division and naming of individual phases and in scope of a factory life cycle. While the definition of "VDI" only takes into account the range from the specification of the target to the ramp-up of production, DOMBROWSKI et al. extends this area to the entire factory life cycle. They also includes the areas of operation and shutdown implecating the sub-categories industrial wasteland, re-utilization and revitalization [10]. While the basic procedure for planning a factory has remained almost unchanged in recent years, numerous changes have been made in the methods and tools available for planning. Especially in the field of digital tools, scores of technology innovations offer additional potential throughout the planning process and thus also for the ramp-up phase. The set of different digital models, methods and tools that are integrated by a continuous data management system can be summarized under the term Digital Factory and have the common aim of "holistic planning, evaluation and ongoing improvement of all main structures, processes and resources of the real factory in conjunction with the product." [2]

With the help of these assistance systems for planning, factory and production structures can be planned in a targeted and standardized manner. Planning errors, for example through false acceptances and the violation of legal restrictions, can be identified in a very early planning phase and be corrected before the implementation. This results in a significant shortening of the necessary planning time and in an increase in the planning quality in which the consequences of the decisions made on the entire lifecycle of a factory become clear. The results of a German study conducted in 2009 show that planning errors can be reduced by up to $70 \%$ by using the classic methods and tools of the Digital Factory. In addition, these results show that planning time could be reduced by up to $30 \%$, change costs by $15 \%$, investment costs by $10 \%$, manufacturing costs between $3 \%$ and $5 \%$. It was also possible to increase product and machine maturity by $12 \%$. [11]

Based on existing findings, a qualitative online survey of 97 German companies was conducted at the Institute for Advanced Industrial Management in 2018 to investigate the effects 
of the fourth industrial revolution (Industrie 4.0) on the digital factory. The results show that the relevance of the Digital Factory is increasing significantly. For example, $90 \%$ of the companies surveyed agree with the statement that Industry 4.0 will have a major impact on the Digital Factory. In addition, the survey results show that large companies tend to assess their relevance rather higher than small and medium-sized enterprises. [12] This confirms the need to adapt the classic concept of the Digital Factory to ensure the future efficient and profitable use of the Digital Factory.

Based on a literature review, different barriers of the Digital Factory could be identified and evaluated in the study. The results of the evaluation are shown in Figure 2.

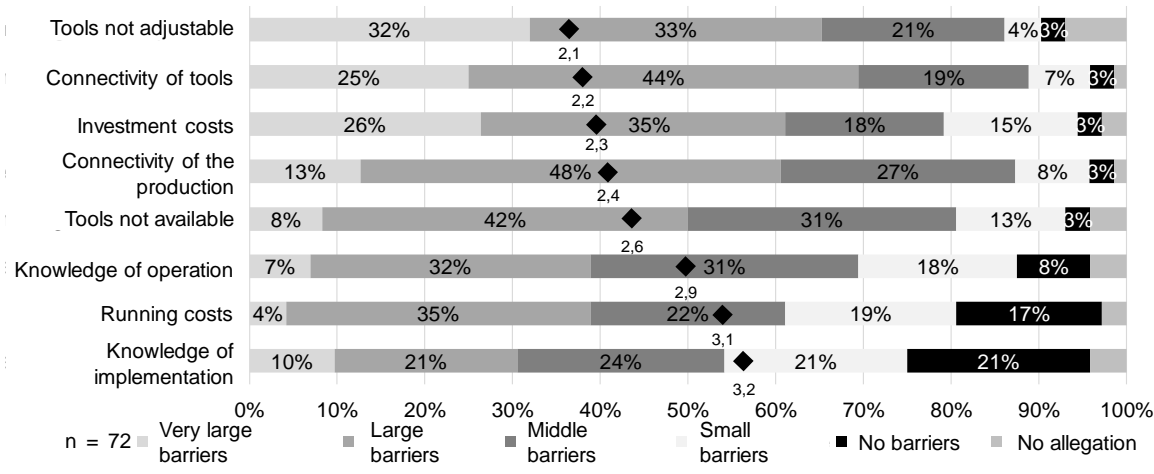

Figure 2: Evaluation of various barriers to the further development of the Digital Factory (based on [12])

The biggest barriers therefore exist in the adaptability and networking of individual tools. More than $80 \%$ of the participants rated these two barriers as at least a medium barrier. The same applies to the general networking of production, which is considered to be very costly and time consuming. Lack of knowledge in the operation and introduction of the Digital Factory is considered as a relatively smaller barrier. Likewise, running costs are not considered a critical barrier to the introduction or development of the Digital Factory. [12]

To solve these barriers, there are already individual approaches that, for example, concern the reengineering of classic factory planning processes to the new requirements. [10] It has also been shown in isolation how tools of factory planning have to be designed in terms of content and user-specific needs for these future requirements. [10], [13]

In particular, for the establishment of bidirectional data management, the continuous networking of tools represents a very relevant barrier for which no concrete results and design notes exist yet. To remove the barrier of data-to-data-networking between factory planning and operations it requires a more detailed view of each digital tool and how it interacts.

In order to consolidate the current state of implementation of the Digital Factory, a study was conducted in the form of expert interviews with a German automobile manufacturer. In the course of the interviews, existing processes were identified through a systematic survey of the experts and the methods and tools contained therein were classified. The processes were then arranged along the entire product development process.

Both the industry and the company were deliberately selected due to the high degree of maturity of existing digital tools. It thus provides a very good basis for relevant insights. A summary of these results is shown in Figure 3. 


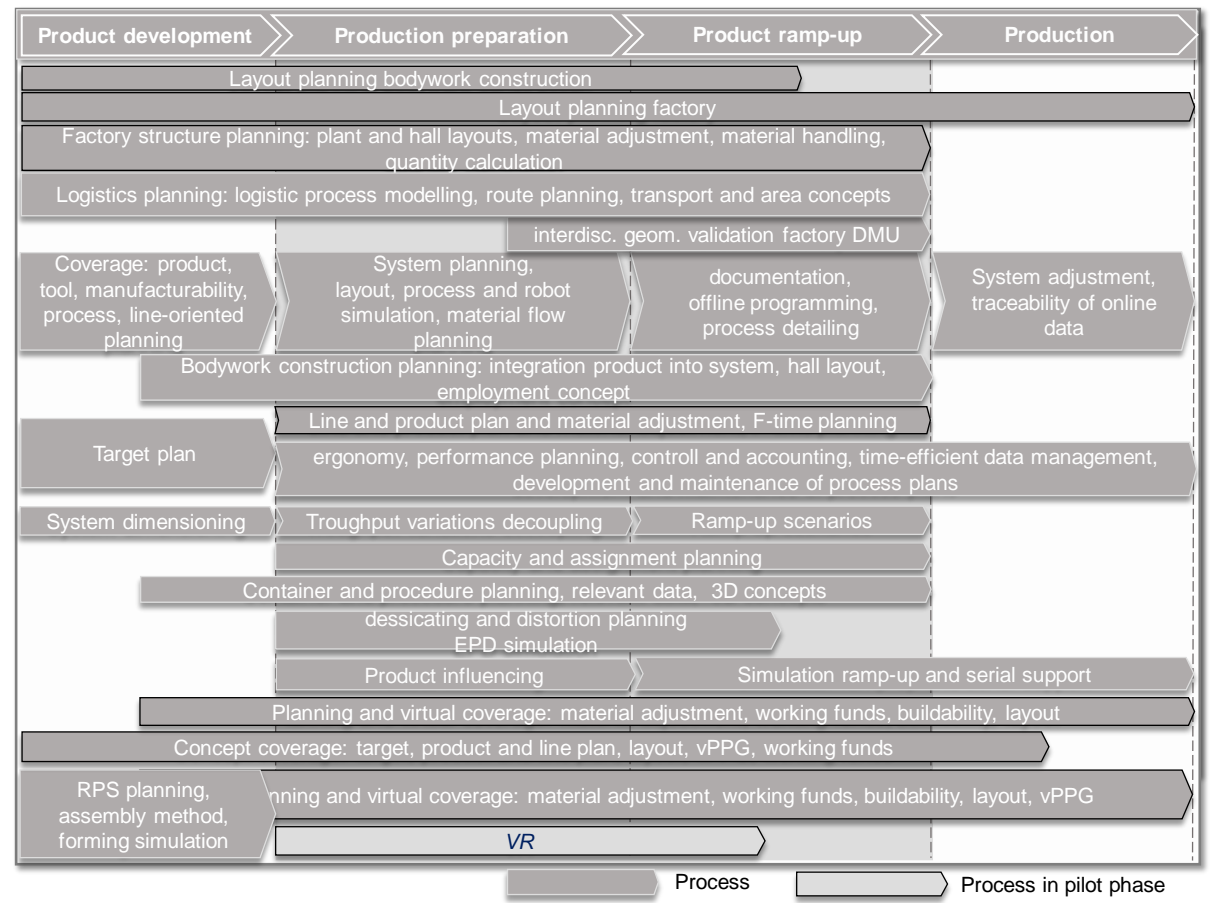

Figure 3: Current implementation status of a German OEM

It is noticeable that the analyzed systems are mainly used in the development phase and the ramp-up phase. Especially from the transition of the ramp-up to the production phase ("SOP"), fewer processes are supported digitally by the named systems. According to the expert interviews, this is due to the lack of up-to-date and permanent data from real production. Without these data, Digital Factory systems can not be enriched. Again, the relevance of bidirectional data management becomes clear. In addition, it becomes clear that the first lever can not be done without a specific analysis of the real data. The two levers thus depend directly on each other.

\subsection{Lever 2: Enrichment of planning data}

The second lever that can help to close the ramp-up data gap is the usage of real data generated in the operation phase. Therefore, it is necessary to understand and define what kind of data is available in production and can be useful in the early ramp-up phase or in the digital factory. If stable state of series production level is reached, more and more data is tracked, documented and used for continuous improvement of the value added processes. In order to close the ramp-up data gap, the permanent real-time availability of data would be an ideal situation [4]. However, in terms of cost-benefit relationship in practice, it is not economical to track every data in real-time from the beginning. This is because complexity of ramping-up the necessary cyber-physical production system would increase tremendously. In turn, this would lead to even higher instability and coordination expenses. This dilemma 
can be defined as "Real-time ramp-up data dilemma". [5] To solve this conflict, it is necessary to analyze what data would be especially helpful in production ramp-up phase in realtime in order to focus on generating this data when setting up future ramp-up scenarios. To evaluate this research question a qualitative data collection approach was conducted in the form of workshops discussions and interviews with production experts from a German commercial vehicle manufacturer. After introducing the research topic to the experts, the general categories from a cause-and-effect diagram were presented to the experts (compare Fig. 4). This classification seems to be helpful since those areas are of special relevance for highly qualitative processes. In a brain writing phase, the participants, who are operational leaders, ramp-up managers and process experts, were asked to identify the four most relevant data types. After discussing the individual ideas, the answers were categorized, prioritized and summarized as shown in Figure 4.

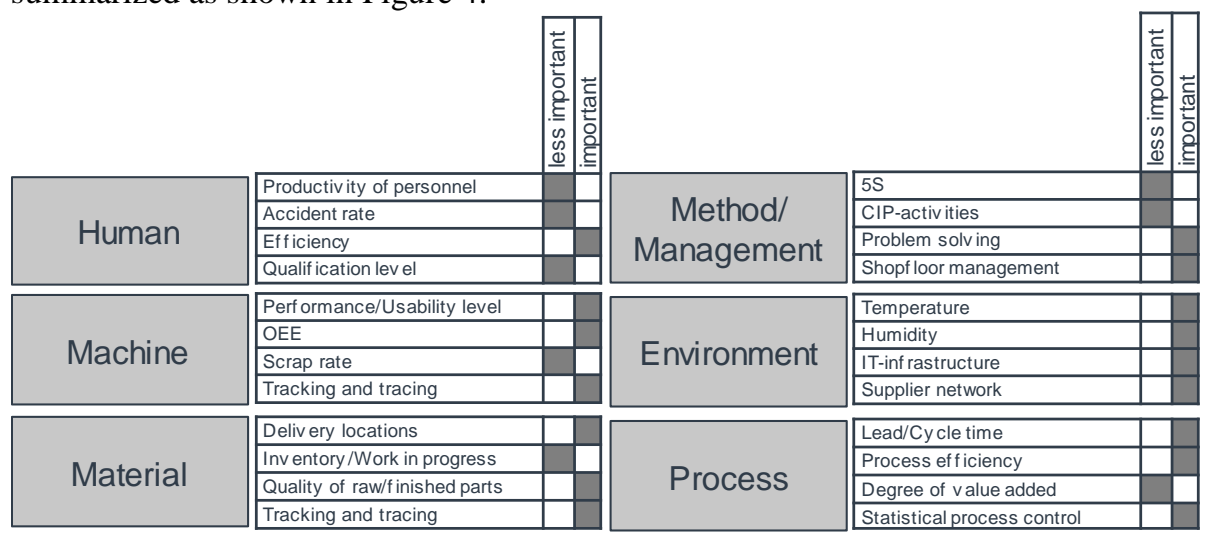

Figure 4: Importance of real-data in production ramp-up

It can be derived that real-time data that has a direct impact on the overall quality of the value added processes, such as efficiency of personnel, quality of raw and finished parts, or problem solving issues is identified to be particularly helpful in production ramp-up. Also, data that is helpful in order to monitor certain process deviations, such as OEE, tracking and tracing of machine and material parameters, or statistical process control has been identified by the experts to be very beneficial. Other data, such as $5 \mathrm{~S}$ activities or accident rates is identified to be less important in real-time.

Despite the fact that the results from the different research studies show clear evidence that both levers can help to minimize or close the ramp-up data gap, the next step is to analyze practically how both approaches can be integrated in order to jointly optimize the ramp-up phase.

\section{Practical validation and results}

At the Center of Excellence for Lean Enterprise $4.0(\mathrm{CoE})$ at Institute for Advanced Industrial Management (Technical University Braunschweig) a restriction-free research environment was set up in which all components of a factory are interconnected and their communication with each other can be experienced in real time [14]. In order to analyze how the 
bidirectional data management approach can help to close the ramp-up data gap, the following use-case studie has been carried out.

Research design: In the CoE, participants can experience production of a simple product. Before starting series production phase, the participants are asked to plan the production system virtually and by using digital factory tools. In the second phase, the participants are asked to launch production and try to fulfill customer demands in the shortest time possible. The "time-to-market" is measured by a time-keeper. In the third phase, the participants are asked to launch production again and constantly improve ramp-up phase by making use of the bidirectional data management approach. Again, the "time-to-market" is measured by a time keeper. After completing all rounds, the participants share their experiences of round two and three in a guided discussion/interview session.

Research results: In this specific use case, focus was on using real data about Material and Machines (compare Fig. 4). Therefore, RTLS-sensors were placed on every machine, workstation and container and thus could be tracked and traced in real time. Additionally, RFID sensors were attached to every part/material so that material flows could also monitored permanently. The participants started to rearrange the production layout in order to improve material flows. Since the cyber-physical production system in the $\mathrm{CoE}$ is interconnected with the digital factory tools, real data from the RTLS and RFID sensors could be integrated in the virtual planning model that has been created by the participants on the planning table beforehand. The real-time data from the changed production system layout could be used to perform a new material flow calculation as well as a walking-routine-optimization on the planning table. As a result, a U-shape machine layout including a changed workplace layout was suggested to be best alternative. Since the possible improvement was presented to the participants via VR-glasses and the virtual planning table, the improvement could be transferred to the real production system immediately. As a result, the time-to-volume could be reduced by about $30 \%$.

The research findings from the three areas above have shown that the ramp-up data gap can not be eliminated by a singular lever. Rather, the interactions of both levers should be considered. Overall, the following key findings can be summarized:

Human level: At the human level, the continuous support of the employee through information is necessary. CIM (Computer Integrated Manufacturing) has focused on providing rapid data delivery that evolves over time as the Digital Factory continues to evolve toward transparent information processing. Increasingly, the focus is on the pure quantity of information, but on the qualitative preparation of the information in a digital assistant for a meaningful and transparent decision-making basis. To close the ramp-up data gap, humans need to be assisted by real-data and/or enriched planning data that is provided user-oriented (e.g. VR/AR, digital planning table).

Organization: On an organizational level, the increasing relevance of the "frontloading" design field, which aims to shift the processes to tasks in the early phase of planning, can be identified. This process relocation should identify planning errors early on and keep the associated change costs as low as possible. If the focus here was first on process integration, there is an increasing abolition of company boundaries and operator models. Regardless of frontloading, process organization is also gaining in importance. Only through a consistent process orientation, relevant data can be provided effieciently by making use of digital tools in the production ramp-up phase. 
Technology: In the CIM approach, a common use of data can be primarily identified as an important task field. Due to the ongoing fourth industrial revolution, larger amounts of real data and increasing interconnections are the core areas of current technical challenges. In future, the focus is on enrichment of planning data with real data in order to improve the quality of the 'digital shadow'.

\section{References}

1. Lanza G, Sauer A (2012) Simulation of personnel requirements during production ramp-up. Prod. Eng. Res. Devel. 6(4-5): 395-402. doi: 10.1007/s11740-012-0394-6

2. The Association of German Engineers (2008) VDI 4499, Part 1: Digital factory: Fundamentals. Beuth

3. Bauernhansl T, Hompel M ten, Vogel-Heuser B (2014) Industrie 4.0 in Produktion, Automatisierung und Logistik: Anwendung, Technologien, Migration. SpringerLink. Springer Vieweg, Wiesbaden

4. The Association of German Engineers (2011) VDI 4499, Part 2: Digital Factory Operations. Accessed 01 Oct 2018

5. Dombrowski U, Wullbrandt J, Krenkel P (2018) "Industrie 4.0 in production ramp-up management". Procedia Manufacturing 17: 1015-1022. doi: 10.1016/j.promfg.2018.10.085

6. Schuh G, Stölzle W, Straube F (2008) Anlaufmanagement in der Automobilindustrie erfolgreich umsetzen: Ein Leitfaden für die Praxis. VDI-Buch. Springer, Berlin, Heidelberg

7. Lanza G (2005) Simulationsbasierte Anlaufunterstützung auf Basis der Qualitätsfähigkeiten von Produktionsprozessen(127)

8. Dombrowski U, Stefanak T, Krenkel P (2017) Aspekte der Fabrikplanung für die Ausrichtung auf Industrie 4.0. In: Reinhart G (ed) Handbuch Industrie 4.0: Geschäftsmodelle, Prozesse, Technik. Hanser, München, pp 169-190

9. The Association of German Engineers (2009) VDI 5200: Factory planning - Planning procedures. Beuth, Berlin

10. Dombrowski U, Karl A, Reiswich A (2018) Reengineering of Factory Planning Process for the Realization of Digital Factory 4.0. Accessed 26 Mar 2019

11. Bracht U, Spillner A (2009) Die Digitale Fabrik ist Realität: Ergebnisse einer Umfrage zum Umsetzungsstand und zu weiteren Entwicklungen der Digitalen Fabrikplanung bei deutschen OEM. ZWF 104(7-8): 648-653

12. Dombrowski U, Karl A, Ruping L (2018) Herausforderungen der Digitalen Fabrik im Kontext von Industrie 4.0. ZWF 113(12): 845-849. doi: 10.3139/9783446437029

13. Dombrowski U, Reiswich A, Karl A (2018) Designing digital tools for factory planning: Integrating requirements for usability on a meta-level. In: Proceedings 2018 IEEE 23rd International Conference on Emerging Technologies and Factory Automation (ETFA): Politecnico di Torino, Torino, Italy, 04-07 September 2018. IEEE, Piscataway, NJ, pp 99-106

14. Dombrowski U, Wullbrandt J, Fochler S (2019) Center of Excellence for Lean Enterprise 4.0. Procedia Manufacturing 31 (9th Conference on Learning Factories 2019) 31: 66-71. doi: 10.1016/j.promfg.2019.03.011 